\title{
Estudio bibliométrico del constructo teórico "víctima": Acercamiento a partir del conflicto armado en Colombia*
}

\author{
Bibliometric study of the theoretical \\ construct "victim": An approach based \\ on the armed conflict in Colombia
}

DOI: https://doi.org/10.17981/juridcuc.18.1.2022.05

Fecha de Recepción: 04/27/21. Fecha de Aceptación: 09/24/21

\author{
Deisy Milena Sorzano Rodríguez \\ Cetys Universidad. Tijuana (México) \\ milena.sorzano@cetys.mx \\ Esthela Galván Vela \\ Cetys Universidad. Tijuana (México) \\ esthela.galvan@cetys.mx \\ María Eugenia Bonilla Ovallos \\ Universidad Autónoma de Bucaramanga. Bucaramanga (Colombia) \\ mbonilla566@unab.edu.co \\ Rafael Ravina Ripoll \\ Universidad de Cádiz. Cádiz (España). \\ rafael.ravina@uca.es
}

Para citar este artículo:

Sorzano, D., Galván, E., Bonilla, M. \& Ravina, R. (2022). Estudio bibliométrico del constructo teórico "víctima": Acercamiento a partir del conflicto armado en Colombia. Jurídicas CUC, 18(1), 109-134. DOI: http://dx.doi. org/10.17981/juridcuc.18.1.2022.05

\section{Resumen}

El presente artículo tuvo por objetivo abordar la red conceptual de la acepción "víctima", a través del señalamiento de los orígenes, recorrido teórico y revisión de las aportaciones científicas al concepto, para ser aterrizado en el ejemplo ilustrativo de la victimización a partir del análisis del caso del conflicto armado colombiano, con el ánimo de establecer el alcance y las limitaciones existentes del objeto de estudio. Aunado a esto, se realizó también un análisis documental, por lo que se presentan los datos obtenidos de la revisión bibliométrica, referente a los trabajos de este campo publicados desde 1984 hasta el año 2020. Para este propósito se hizo búsqueda de datos en Scopus, base de datos bibliográfica global y de alta calidad, localizando 1 mil 928 documentos, de los que se destacan los autores, las regiones, las afiliaciones instituciones, los periodos de publicación, las definiciones más representativas, entre otros datos relevantes, concluyendo en la necesidad de reivindicar los vacíos existentes en cuanto a la claridad del concepto, la notoria ausencia de investigación en países como Colombia frente al considerable aporte de territorios como Estados Unidos y, en términos generales, la invisibilidad de la producción de calidad latinoamericana.

Palabras clave: Víctima; bibliometría; conflicto armado; Colombia

\begin{abstract}
The objective of this article was to address the conceptual network of the meaning "victim", through the indication of the origins, theoretical journey and review of the scientific contributions to the concept, to be landed in the illustrative example of victimization based on the analysis of the case of the Colombian armed conflict, with the aim of establishing the scope and existing limitations of the object of study. In addition to this, a documentary analysis was also carried out, for which the data obtained from the bibliometric review are presented, referring to the works in this field published from 1984 to 2020 . For this purpose, a data search was made in Scopus, global and high-quality bibliographic database, locating 1 thousand 928 documents, of which the authors, regions, institutional affiliations, publication periods, the most representative definitions, among other relevant data, stand out, concluding in the the need to vindicate the existing gaps in terms of the clarity of the concept, the notorious lack of research in countries such as Colombia compared to the considerable contribution of territories such as the United States and, in general terms, the invisibility of quality Latin American production.

Keywords: Victim; bibliometric; armed conflict; Colombia
\end{abstract}

(c) The author; licensee Universidad de la Costa - CUC.

JURÍDICAS CUC vol. 18 no. 1, pp. 109-134. Enero - Diciembre, 2022

Barranquilla. ISSN 1692-3030 Impreso, ISSN 2389-7716 Online 


\section{INTRODUCCIÓN}

Intentar definir conceptos, es una tarea que resulta un tanto compleja por los diferentes matices que estos pueden incluir. Para Vygotsky (1964), la construcción conceptual es "un proceso paulatino que incluye una compleja red de relaciones neuronales, sociales y sobre todo culturales" (p. 415). En el caso particular de este artículo, que se genera como resultado del proyecto de investigación titulado: "Factores prolongadores del conflicto armado en Colombia desde la perspectiva FARC-EP"1, hablar de víctima, que es la cuestión base de la presente revisión bibliográfica y análisis bibliométrico, "involucra un intento por comprender la realidad de algunas personas, concebida desde diferentes esferas como aquellas que afirman que hablar de víctimas es hablar de clases oprimidas, clases esclavizadas" (Reyes, 2006, p. 17), hasta posturas que señalan que "la acepción está relacionada con el impedimento a la producción, reproducción y aumento de su vida en sociedad" (Dussel, 2001, p. 36), lo que ha originado múltiples aportes para dirigir los esfuerzos a posibles situaciones de reparación, a través de reflexiones históricas, éticas, filosóficas, económicas y políticas para su establecimiento como fenómeno social.

Con relación a esto, el artículo está estructurado de la siguiente manera: En la parte inicial se incluye el recorrido por conceptos y acercamientos a la acepción de víctima exponiendo los aportes de autores como Neuman (1994), Shklar (2013), Dussel (2001), Reyes (2008), entre otros, para establecer y caracterizar quién es realmente una víctima y su papel como sujeto pasivo o activo. Seguidamente, se describe el ejemplo ilustrativo de víctima a partir de la concepción de sujetos involucrados al conflicto armado en Colombia mediante técnicas interpretativas que orillan a plantear el supuesto de que la acepción de víctima desconoce algunos elementos para su pleno reconocimiento, en lo que también es importante señalar que el concepto de investigación es impreciso en cuanto a

\footnotetext{
Realizado por una de las autoras (Deisy Milena Sorzano), como requisito de titulación para la obtención del grado de Doctor en la Universidad Autónoma de Baja California (México).
} 
una definición única, ya que incluye diferentes matices y puede hacer referencia a diferentes áreas de conocimiento. Aunado a esto, se realiza una revisión de la literatura concerniente al estado del arte de la investigación en este campo, permitiendo el análisis de la cantidad y calidad de las publicaciones científicas que se han realizado desde el ámbito de las ciencias sociales, específicamente, mediante técnicas bibliométricas a fin de verificar la situación actual del constructo en el ámbito académico, finalizando con la generación de conclusiones.

\section{Desarrollo}

\section{Acercamientos a la acepción "víctima"}

Los debates y disyuntivas acerca de la palabra "víctima" son amplios y cada día más complejos, según la postura e ideología de quienes intentan explicar este concepto sociológico y fenómeno social. Para llegar a acercamientos preliminares se debe partir del contexto víctima-dignidad, elementos que entretejen una relación directa y proporcional que se encuentra medida por otros innumerables elementos. De acuerdo con esto ¿es posible concebir como víctima al sujeto cuya dignidad humana ha sido afectada por la violencia y/o violación de sus derechos fundamentales?

Responder a este interrogante, también requiere definir: ¿quién es realmente una víctima?, ¿en qué condiciones es considerada una persona como víctima?, ¿qué elementos son incluidos en la concepción de víctima?, ¿se pueden incluir otras categorías de análisis como justicia, para la definición de este vocablo?

De acuerdo a esto, se puede afirmar que la génesis de la acepción está enmarcada en el aporte de Neuman (1994), para quien el término "se deriva del concepto Venceri, que hace alusión a los animales que se sacrificaban a los dioses o deidades como representación de un sacrificio, donde la víctima era la ofrecida por cumplimiento de tal acto" (p. 27), lo que coincide con los aportes de Shklar (2013), en cuanto: 
La acepción era utilizada inicialmente para referirse a las criaturas que eran sacrificadas y asesinadas en aras de alguna omnipotencia y sólo a partir del siglo diecisiete se ha aplicado a las personas que eran sometidas a la muerte o a un trato cruel y opresivo (p. 82).

Así mismo, "desde el homosapiens, la evolución víctimal corre pareja con la evolución creativa de los derechos humanos" (Beristain, 2000 , p. 85), cuestión que puede ser dilucidada como la constante relación que ha existido desde tiempos de antaño entre la noción de víctima y los derechos humanos, argumento extendido hasta la actualidad donde existen manuales de protocolos, según los derechos humanos, de cómo tratar a una víctima.

¡He aquí una víctima! La primera condición de posibilidad de la crítica es, entonces, el reconocimiento de la dignidad del otro sujeto, de la víctima, pero desde una dimensión específica: como viviente. Este «conocer» a un ser humano desde la vida; este «re-» conocerlo: conocerlo" desde» su vulnerabilidad traumática. Este volver sobre su estado empírico negativo y «re-conocerlo» como víctima (es decir, faltante de vida en alguna dimensión, o no realización pulsional en cuanto a la auto conservación), es el momento analéctico de la dialéctica y que nos permite subsumir todo lo ganado en la primera parte (Dussel, 2001, p. 93).

Partiendo de esto, Dussel (2001) asevera que:

Para hablar de esta concepción se requiere imperantemente hablar del reconocimiento de su dignidad, de su papel como humano y se adquiere la categoría de víctima en el momento en que alguna área de su vida se ve afectada, al igual que se deben tener en cuenta elementos como la memoria al considerar a la víctima como sujeto histórico. En este sentido los vencidos/víctimas, no sólo son aquellos que perdieron una guerra, si no los que hacen parte permanentemente de los sistemas de dominación (p. 93).

Lo que relaciona víctima a oprimido, y también incluye esta categoría "a quienes no le son dadas oportunidades por la sociedad, siendo está situación en detrimento del bienestar" (Rojas, 2014, p. 11). 
Por lo que una víctima:

Si bien puede ser un abrumado, puede ser una persona obrera, esclavo o explotado, de cualquier nacionalidad, raza, sexo o condición sufrida por destrucción ecológica o por ser parte de la sociedad de consumo, así también los niños abandonados, los inmigrantes, entre otros (Dussel, 2001, p. 93).

Generando un categoría global del concepto. Estas definiciones se han transformado y se han extendido, hasta llegar a designar al conjunto de personas que han recibido menos de lo que les correspondía.

Por su parte Montaige y Montesquieu hablan de "la tendencia general de los seres humanos hacia la crueldad, cuestión contraria a lo que debe primar en la vida en sociedad" (Shklar, 2013), destacando a víctimas y victimarios. A su vez, Mendelshon (1963), quien ha sido catalogado como el padre y precursor de los estudios relacionados con esta área, define víctima "a través de la relación entre víctima e infractor, realizando una clasificación de grandes grupos" (p. 619), aunadamente al trabajo realizado por Henting (1971), quien clasificó a las víctimas "a partir de elementos psicológicos y posibles situaciones de acción del agresor" (1971, p. 56).

En concordancia, teniendo como punto de elucidación el papel de la víctima, se pueden identificar algunos aportes antagónicos como los de Dussel (2001) y Shklar (2013), donde Dussel (2001), afirma que "la víctima es activa y está comprometida en su auto liberación" (p. 38), mientras para Shklar (2013) la condición de víctima es "una noción pasiva o inactiva, lo que podría ser interpretado bajo la generalidad que no tiene poder de decisión y está condicionada y sometida a la acción del victimario" (p. 72). Aunado a la incomodidad y grado de dificultad que conlleva el auto denominarse como víctima:

A la mayoría de la gente no le gusta verse como víctimas porque, después de todo, no hay nada más degradante. La mayoría de nosotros preferimos reordenar la realidad más que admitir que somos indefensos objetos de una injusticia. Hasta el autoengaño parece mejor que admitir lo primero (Shklar, 2013, p. 72). 
Dentro de este contexto, si bien, Rousseau (Shklar, citado por Rojas, 2014), "tiene en cuenta la indignación por la injusticia, y por una sociedad inicua que desfigura los sentimientos morales de las personas que la componen" (p. 66). Sen (citado por Rojas, 2014), señala que "esto es resultado de la desigualdad y las privaciones de los contextos" (p. 49), lo que coincide con el planteamiento inicial y define como víctima a:

Un ser que se encuentra en condiciones de desigualdad, encontrándose en un estado de privación enquistada, experimentado en el fenómeno de adaptabilidad que consiste en que las víctimas reducen sus deseos o expectativas a las pequeñas misericordias que pueden obtener y no al desarrollo real de su libertad y de sus capacidades (Rojas, 2014, p. 73).

Otras distinciones señalan que no todos los individuos que sufren, son necesariamente víctimas, por lo que la acepción sería impensable sin un correlato de verdugo, o de quien genera el daño (Reyez, 2008). Por lo que no se puede pensar en que una víctima sea quien sufre de violencia natural o quien solo sufre por el hecho de sufrir.

Reyes (2008) ilustra sus argumentos en el sufrimiento de los nazis condenados, quienes sufrían a pesar de no ser víctimas; por lo que alude a que la inocencia es una característica de quien es realmente una víctima. Así también argumentó: “[...] esto no significa que podamos pasar de largo ante el sufrimiento del verdugo. Todo sufrimiento interpela, pero el de la víctima de una manera especial porque es inocente" (Rojas, 2014, p. 67), haciendo así una clara diferenciación entre víctima y victimario, aunque son categorías que no se pueden disgregar.

Por su parte, en otros aportes, Levi (1989) detalla el término "zona gris", contemplando que no existe una posición absoluta entre víctimas y verdugos, y si una intersección entre ambas, en otras palabras: "Es una zona gris de contornos mal definidos, que separan y unen al mismo tiempo a los dos bandos de patrones y de siervos" (Levi, 1989, p. 51). 
Con ello se comprende la posibilidad de que una víctima pueda llegar a convertirse en verdugo, que el verdugo se transforme en víctima, o que sean a su vez sus propios verdugos. Levi (1989) indica que todos los individuos son susceptibles de caer en esa zona de ambigüedad cuando se ven cegados por el poder y el prestigio. Aunado a esto, una víctima es aquella persona inocente que ha sido objeto pasivo de las acciones perjudiciales de otros hacia ella. En esta definición se hace uso de la expresión "víctimas inocentes", para resaltar como esos individuos no son responsables por dichos actos y sus derechos fueron violentados generándoles un daño. Asimismo, plantea la clara distinción moral entre: perpetrador y víctima, donde el perpetrador al realizar una acción perjudicial y mala hacia otro ser humano, se convierte en un agente activo, es decir, se transforma en el sujeto del acto, quien es presumiblemente responsable de él y culpable por su comportamiento.

De esta manera y al tener un puente conceptual, como el descrito anteriormente que facilita la comprensión del fenómeno social objeto de estudio desde un enfoque general, se puede esclarecer el siguiente interrogante: ¿De qué manera la conceptualización de los Derechos Humanos está aunada a las víctimas? En la declaración, sobre los principios fundamentales de justicia para las víctimas de delitos y de abuso del poder se considera como víctima a "las personas que, individual o colectivamente, hayan sufrido daños, inclusive lesiones físicas o mentales, sufrimiento emocional, pérdida financiera o menoscabo sustancial de los derechos fundamentales, como consecuencia de acciones u omisiones que violen legislaciones penales" (Comisión Nacional de los Derechos Humanos-CNDH, 2018, p. 1). A partir de esta definición se orientan acciones relacionadas con acceso a la justicia, trato justo, resarcimiento, indemnización y asistencia para su trato.

Es importante mencionar que existen incontables elementos aparte de los ya señalados para continuar con la conceptualización, como las discusiones entre las formas de actuación ante quien tiene el papel invisible de una víctima y de quien tiene el papel protagónico, es decir, su agresor o victimario. Además de los enfoques específicos a nivel jurídico-penal en cuanto a castigos y leyes; a nivel ético-moral en lo que se refiere al debate de la culpabilidad de la víctima frente 
al hecho; a nivel psicológico en tanto se tenga en cuenta la propensión y vulnerabilidad de la persona como sujeto individual a ser víctima de algún hecho o acto; el nivel político, que se referiría al papel del Estado como arquitecto de la realidad social, garante de la protección de la persona y defensor de los derechos fundamentes de su población, por lo que algunas interpretaciones, están relacionadas con el reconocimiento a la vida y a la paz como un derecho de cumplimiento obligatorio, donde el Estado tiene el deber inexcusable de hacer valer la vida de las personas bajo su jurisdicción (Narváez, Matzumoto, Mira y Zúñiga, 2019).

\section{Definición de víctima a partir del caso colombiano}

Al considerar la importancia de los estudios a nivel particular y dado que toda sociedad tiene una historia propia, a continuación, se expone el acercamiento a la noción de víctima a partir del conflicto armado colombiano, considerando las implicaciones de este.

Las difíciles condiciones sociales y económicas del territorio colombiano expresan las cifras exponencialmente negativas que datan de tiempos remotos, los cuales señalan la presencia de fuertes problemas como pobreza, desempleo, inflación, carencia de oportunidades, desigualdades económicas, ausencia de un sistema de salud de calidad entre otros (Robinson, 2016), que deja días tras día un número elevado de víctimas. Bajo este contexto señalar la prolongación por más de cincuenta años de un conflicto armado, problemática más antigua del hemisferio occidental, ha sido tema central de incontables investigaciones y definiciones, donde "algunas perspectivas, lo catalogan como un conflicto social armado, otras, guerra civil, guerra o un conflicto irregular, por lo que para generalizar estas nociones, se podría hablar de conflicto armado interno", como es señalado por Hernández, Cerpa y Molina (2020, p. 239), cuestión que también implica hablar de sujetos dañados, ya que "ha causado fuertes impactos negativos sobre el desarrollo humano y todos sus indicadores, la lucha contra la pobreza, la gobernabilidad, la transparencia, la equidad, los derechos humanos y el fortalecimiento de sentido de lo público" (Programa de las Naciones Unidas para el Desarrollo-PNUD, 2014, p. 1). 
Los factores que lo han originado y permitido podrían estar determinados por el contexto socioeconómico, socio-político, y socio-militar del país, que junto a fenómenos como el paramilitarismo, el narcotráfico, las guerrillas y la propia acción estatal ha generado miles de afectados, impactando negativamente en el bienestar de la población. Tan solo este primero, ha generado millones de víctimas por conceptos varios como masacres, asesinatos, desaparición forzada, secuestro, desplazamiento forzoso, tortura, reclutamiento forzoso, violencia sexual, entre otros (Villamizar, 2019).

TABLA 1.

Hechos de violencia asociados al conflicto armado.

\begin{tabular}{|c|c|}
\hline Conducta / Hechos de violencia & $\begin{array}{l}\text { Número de casos } \\
\text { documentados }\end{array}$ \\
\hline Homicidios. & 163762 \\
\hline Desaparición forzada. & 31841 \\
\hline Masacres. & 1309 \\
\hline $\begin{array}{l}\text { Reclutamiento de menores (menores identificados } \\
\text { y ubicados como víctimas de reclutamiento). }\end{array}$ & 3557 \\
\hline Desplazamiento forzado masivo (por comunidades). & 66562 \\
\hline Violencia de género. & 552000 \\
\hline Secuestros. & 2860 \\
\hline Extorsión. & 3184 \\
\hline Narcotráfico. & 58000 \\
\hline Otras Conductas. & 25718 \\
\hline $\begin{array}{l}\text { Participación de la fuerza pública con grupos armados ilegales } \\
\text { (citados por postulados en versión libre bajo juramento). }\end{array}$ & 328000 \\
\hline Participación de políticos en grupos armados ilegales. & 404000 \\
\hline
\end{tabular}

Fuente: Elaboración propia a partir de López (2010).

Según datos oficiales, las cifras han aumentado considerablemente al paso del tiempo, como puede evidenciarse en la Tabla 1, donde se relacionan datos del año 2010, que al compararse con las estadísticas actuales permiten dicho análisis. Por lo que en el Sistema Nacional de Atención y Reparación Integral a las Víctimas (SNARIV, 2021) se señala que: 
En dicho periodo cerca de 18.000 menores habían sido reclutados por grupos armados al margen de la ley, aproximadamente 3.888.309 habían sido desplazadas de sus hogares, alrededor de 23.742 personas fallecieron anualmente por causas violentas relacionadas con el conflicto incluyendo personas civiles, fuerza pública y guerrilleros, sin contar la desaparición forzada, las violaciones sexuales, los atentados contra la libertad, el despojo de tierras, las minas antipersonas, los secuestrados, cifras que para el año 2016, aumentaron en más de 158.000 personas. Las víctimas registradas históricamente comprendían el número total de 7.970.190, dato oficial brindado por la Unidad para las Víctimas del gobierno nacional colombiano y para sorpresa negativa, el último dato estimado contabilizó 9.014 .766 víctimas del conflicto armado (párr. 1).

Caracterización que coincide con los aportes de Trejos, Badillo e Irreño (2019), quienes afirman que la conflictividad en subregiones colombianas y por ende las víctimas que estos escenarios generan, obedecen a la presencia de cultivos ilícitos, la emergencia de minería ilegal, el surgimiento de las llamadas GAO (Grupos Armados Organizados) o bandas emergentes y criminales, la presencia de grupos insurgentes y acciones armadas en general determinadas por actores armados específicos, rentas ilegales y el mismo grado de afectación del conflicto.

Entonces, ¿quién es una víctima del conflicto armado colombiano? La Ley 1448 (2011), titulada como "Ley de Víctimas y Restitución de Tierras", específica que una víctima del conflicto armado es:

Aquella persona que individual o colectivamente hayan sufrido un daño por hechos ocurridos a partir del $1^{\circ}$ de enero de 1985 , como consecuencia de infracciones al Derecho Internacional Humanitario o de violaciones graves y manifiestas a las normas internacionales de Derechos Humanos, ocurridas con ocasión del conflicto armado interno, al igual que el cónyuge, compañero o compañera permanente, parejas del mismo sexo y familiar en primer grado de consanguinidad, primero civil de la víctima directa, cuando a esta se le hubiere dado muerte o estuviere desaparecida. A falta de estas, lo serán los que se encuentren en el segundo grado de consanguinidad ascendente y finalmente a las personas que hayan sufrido un daño al intervenir para asistir a la víctima en peligro o para prevenir la victimización (Art. 3). 
Junto a estos elementos, la Corporación de Acompañamiento Psicosocial y Atención en Salud Mental a Víctimas de la Violencia Política (Jalecza, 2008), señala como víctimas a:

La(s) persona(s) de la población civil que, individual o colectivamente, como resultado de actos u omisiones que violan los Derechos Humanos o el Derecho Internacional Humanitario han sufrido daños físicos o mentales, sufrimiento emocional o menoscabo sustancial de sus derechos fundamentales y que cumplen a su vez un papel activo como sujetos políticos y sociales en la exigencia de sus derechos, en la reconstrucción y reivindicación de la memoria histórica y en su recuperación emocional (párr. 3).

Por lo que se destaca la concepción de las víctimas como seres pasivos, no sujetos políticos y que en concordancia con las definiciones iniciales han sido afectadas en su bienestar. Junto a esto, es pausible explicar algunos errores en este reconocimiento: Se habla de una idea homogénea de las víctimas (Bohórquez, Rojas y Anctil, 2017) desconociendo que:

Si bien es una escalofriante comunidad encabezada del sujeto víctima de la guerra, este a su vez incluye el sujeto silencioso: pobre desplazado, el sujeto despojado: desplazado sin recurso compensatorio, el sujeto mujer sin nucleo familiar consolidado, el sujeto niño sin familia, ni futuro y el sujeto violentado, torturado, secuestrado, abusado y desaparecido, por lo que es necesario estructurar un camino que posibilite la definición de Víctima más alla de lo técnico y lo administrativo (Mora-Gámez, 2016, p. 75).

Es importante aclarar en este contexto que "para acogerse a medidas de reparación específicas, también llamada justicia transicional a fin de solucionar el qué hacer con las víctimas" (García, 2019 , p. 383), en donde las acciones cumplen un amplio espectro como la restitución de tierras, indemnización por vía administrativa, medidas de rehabilitación, medidas de satisfacción y garantías de no repetición, las víctimas deben ser declaradas como tales, por medio de una sentencia o pronunciamiento judicial de la Corte Constitucional, por lo que si bien existe un reconocimiento 
jurídico, otros escenarios señalan la ausencia del reconocimiento social y la reparación real, es aún una deuda. Basta con algunas revisiones, para comprender que en el contexto colombiano, la violencia del conflicto, es el generador de víctimas constantes en la historia del país.

\section{MEtodoloGía}

El presente artículo atiende un alcance descriptivo, que está basado en un acercamiento a las nociones de la acepción de víctima, la cual abarca una amplia gama de disciplinas, datos y métodos, lo que puede dificultar su entendimiento. El acercamiento al constructo se logra mediante la revisión bibliográfica de los orígenes y la evolución del término e involucra también un análisis bibliométrico de las publicaciones científicas al respecto mediante el software estadístico R Studio (1.4) y la extensión de Bibliometrix. Se incluyen estas herramientas dada la importancia de la bibliometría al estudiar la "organización de los sectores científicos y tecnológicos a partir de las fuentes bibliográficas y patentes para identificar a los autores, sus relaciones y sus tendencias" (Spinak, 2001, p. 18), aunado a "la necesidad de medir la producción científica, cuantificando la calidad y el impacto de la misma, por lo que la interpretación de las estructuras sociales, intelectuales y conceptuales a través de redes bibliográficas" (Cobo, López-Herrera, Herrera-Viedma y Herrera, 2011, p. 1382) se hace imprescindible.

Como primera medida se hace necesario delimitar el universo de producción, teniendo como caso específico el repositorio científico de revistas de alta calidad de la disciplina de las ciencias sociales identificando un número determinado de artículos y a partir de estos se analizó la temporalidad general de los datos —desde 1948 hasta 2020 - , los años, autores y palabras claves, la participación por país y, así mismo, la identificación de las instituciones que más contribuyen a la creación de conocimiento relacionado con el término víctima, entre otros aspectos relevantes. 


\section{RESUltados Y DISCUSIÓN}

\section{Análisis bibliométrico:}

Aportaciones en el campo a la acepción "víctima"

El análisis a la generación de conocimiento que se realiza desde el ámbito de la aportación científica es importante cuando se busca profundizar en el estudio de un concepto o fenómeno, por lo que las técnicas de bibliometría son una excelente herramienta de evaluación de la calidad de los contenidos científicos y su impacto en el entorno académico, por lo que la relevancia de un análisis bibliométrico recae en el reconocimiento del estado literario desde diferentes perspectivas a fin de identificar oportunidades latentes en la construcción de teoría.

El análisis bibliométrico aquí expresado se logró a través de la búsqueda de datos de Scopus, uno de los principales repositorios de contenidos científicos globales y de alta calidad. La búsqueda se basó en el término "victima", únicamente para las áreas de ciencias sociales, psicología y artes y humanidades, ya que el concepto se encontró presente en otras áreas como la medicina, la ingeniería, las ciencias ambientales, la bioquímica, genética y biología molecular, entre otras. Así mismo, se excluyó la búsqueda a solo artículos empíricos y de revisión, capítulos de libro y libros en español e inglés.

Bajo las anteriores condiciones, se encontró un repositorio científico de 1928 documentos, los cuales fueron extraídos en un archivo de extensión BibText, el cual permite la lectura de los datos almacenados por cada documento en cuanto a autor, afiliación, país, año de publicación, entre otros datos susceptibles de análisis, procediendo continuamente al uso de los software estadísticos de $\mathrm{R}$ y $\mathrm{R}$ Studio, así como a la extensión de Bibliometrix para la extracción y representación de los datos. La información general de datos se presenta en la Tabla 2, en donde se manifiesta que la temporalidad de los documentos científicos sobre el término víctima comprende el periodo de 1948 hasta el 2020, así mismo, el mayor número de contribuciones son de tipo artículo científico, el número de autores fue de 3098 y el promedio de citas por documento analizado fue de 9.59. 
TABLA 2.

Información general de documentos

\begin{tabular}{ll}
\hline \multicolumn{1}{c}{ Información general } & \multicolumn{1}{c}{ Dato } \\
\hline Línea temporal & 1948 a 2020 \\
Número de documentos & 1928 \\
Promedio de citas por documento & 9.59 \\
\hline \multicolumn{1}{c}{ Tipos de documentos } \\
\hline - Artículos científicos & 1384 \\
- Artículos de revisión & 158 \\
- Libros & 129 \\
- Capítulos de libro & 257 \\
Número de autores & 3098 \\
\hline
\end{tabular}

Fuente: Elaboración propia a partir de datos de Bibliometrix.

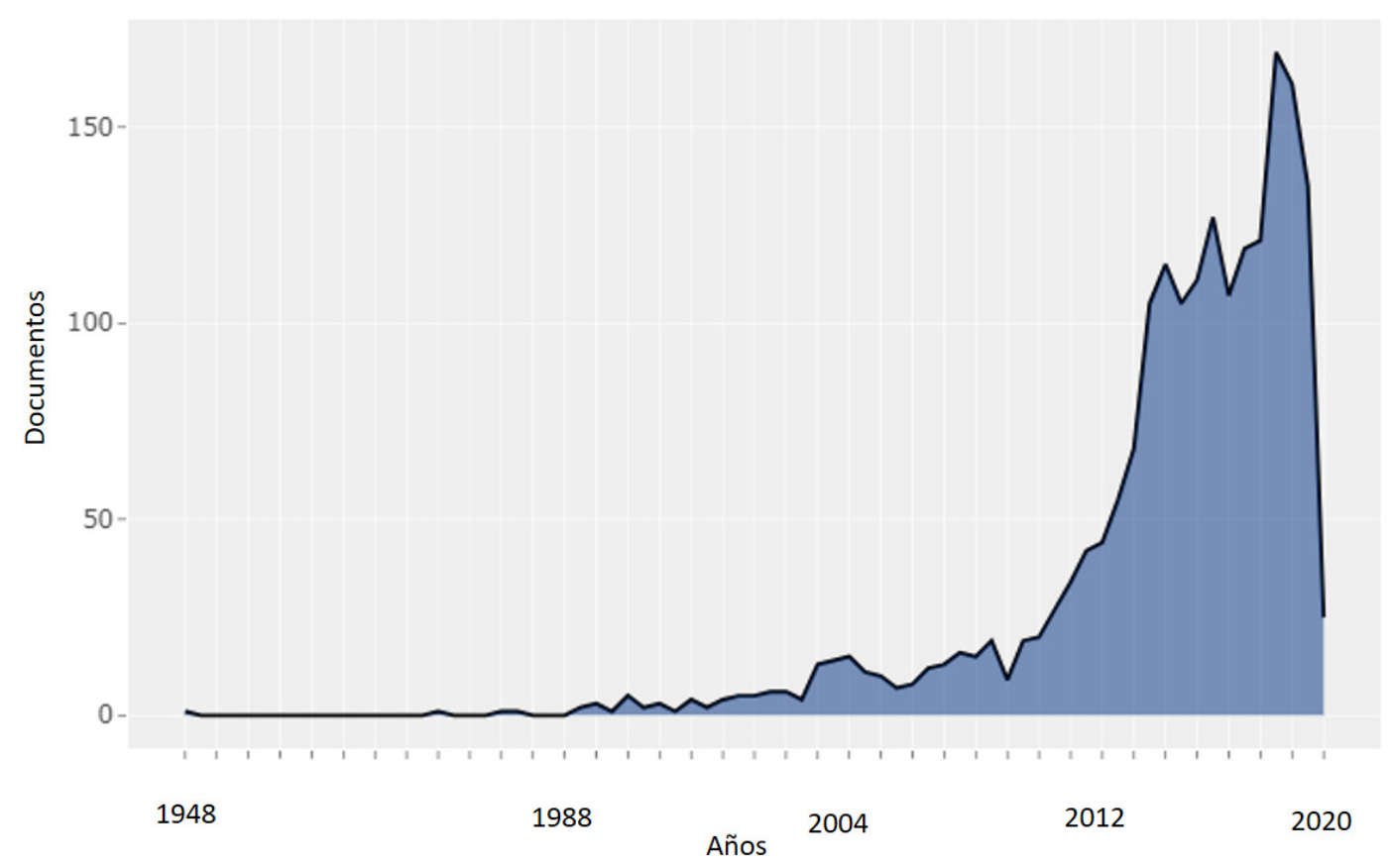

Figura 1. Producción científica anual 1948-2020.

Fuente: Elaboración propia con Bibliometrix a partir de los datos analizados.

A pesar de que la concepción de "víctima" en el ámbito científico se remonta al año 1948, el análisis de las aportaciones muestra periodos dispares en lo que refiere a la cantidad de aportaciones al concepto, como se puede evidenciar en la Figura 1. El primero de 
ellos fue entre 1948 y 1987, años en los que el promedio de publicaciones ascendió a tres (3) documentos anuales.

El segundo fue el periodo comprendido entre 1988 y 2003, cuando en promedio se publicaron 14.25 artículos alusivos al término. El tercero fue entre 2004 y 2011, cuando se publicaron en promedio 71 documentos científicos anuales y, por último, el periodo comprendido entre 2012 y 2020 , en donde se pone en evidencia la importancia atribuida al desarrollo del concepto con un promedio de 119.4 aportaciones científicas anuales (Figura 1).

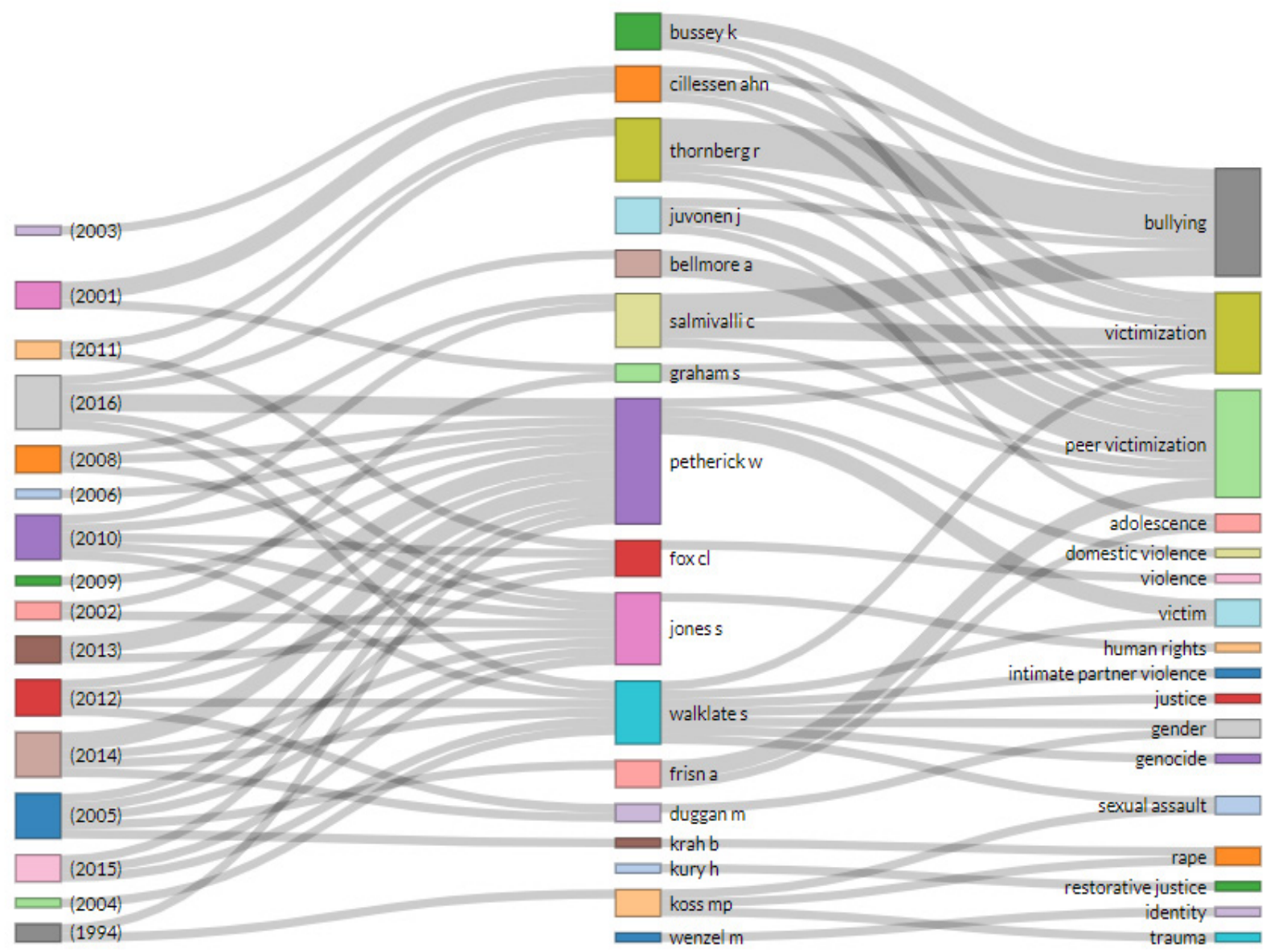

Figura 2. Filtro de 3 campos: años, autores y palabras clave.

Fuente: Elaboración propia con Bibliometrix a partir de los datos analizados.

Un filtro de tres campos o Three-Fields Plot (Figura 2) permitió relacionar años de publicación, con autores relevantes al término de víctima, así como las palabras clave más representativas en los docu- 
mentos. Se puede apreciar en la Figura 2 el bullying, la victimización y la victimización en pareja, como términos altamente relacionados a la palabra víctima. Así mismo, la constante participación de exponentes como Patherick, Jones, Waklate, Fox, entre otros a lo largo de la historia.

Entre otros hallazgos, entre las revistas que más publican información relacionada al concepto de "víctima" se encuentran la Journal of Interpersonal Violence con 82 artículos, la Journal of Youth and Adolescence con 28 artículos, la Violence Against Women con 26 artículos, y la International Review of Victimology con 22 artículos. En la Figura 3 se ilustran las diez revistas con más contribuciones a generar este conocimiento.

\section{Most Relevant Sources}
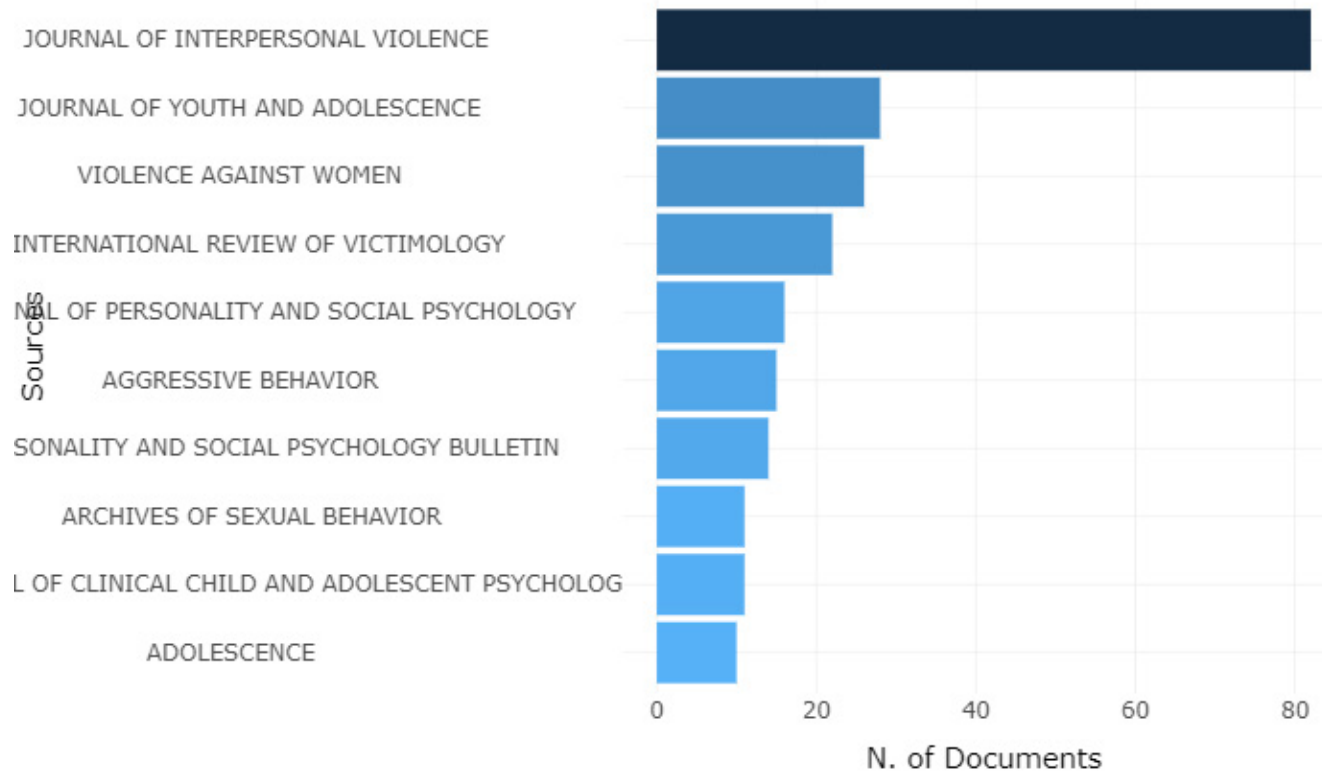

Figura 3. Revistas que más publican sobre el término "víctima" Fuente: Elaboración propia con Bibliometrix a partir de los datos analizados.

Estas mismas revistas, han incrementado de forma acelerada las publicaciones relacionadas al término de "víctima" contribuyendo al crecimiento del conocimiento durante los últimos años, tal como se ilustra en la Figura 4. 


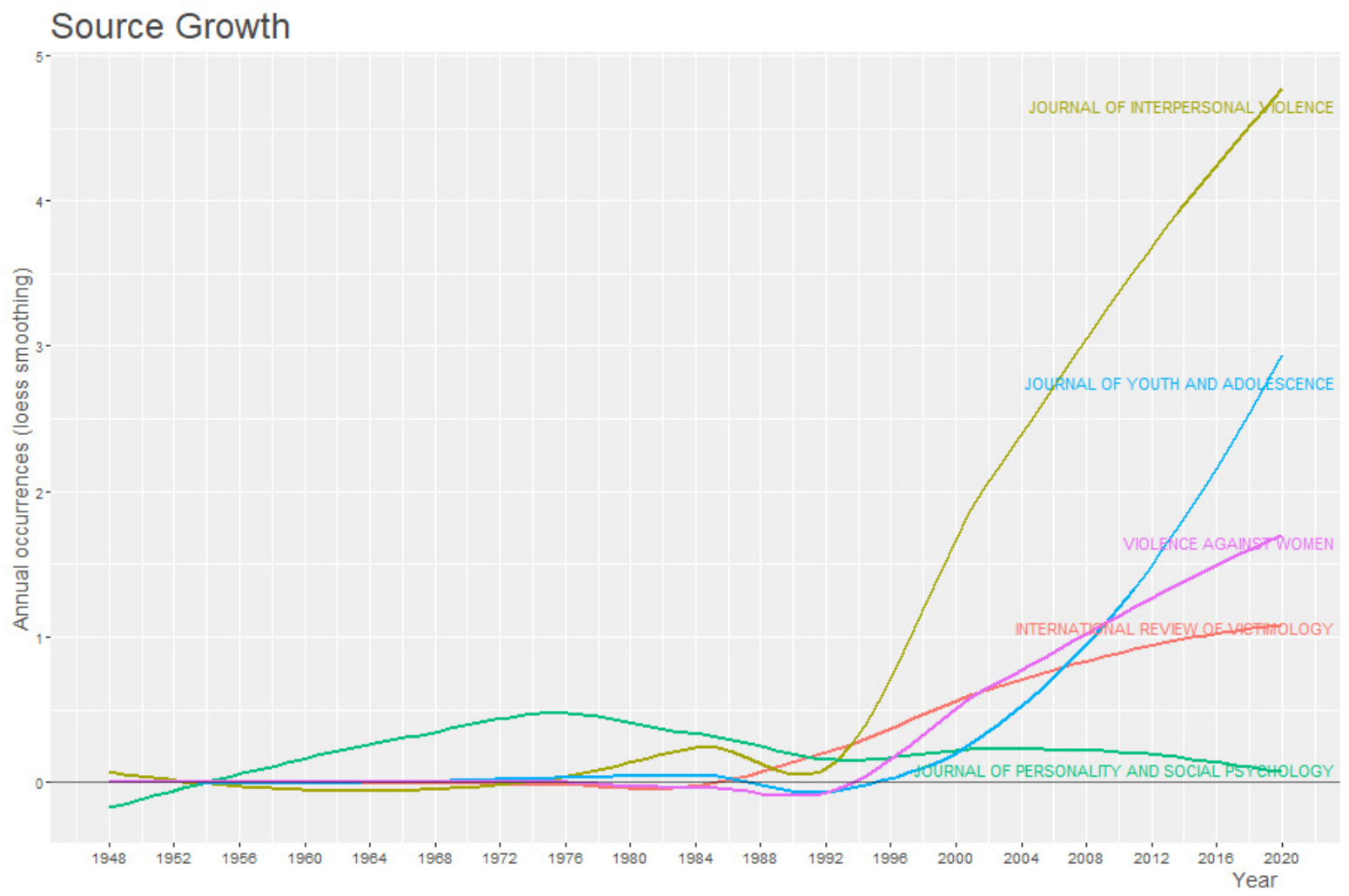

Figura 4. Co-ocurrencia de publicación anual por revistas sobre el término "víctima".

Fuente: Elaboración propia con Bibliometrix a partir de los datos analizados.

Entre los diez países que más contribuyen a la creación de conocimiento relacionado al término de "víctima", se tienen: Estados Unidos con un total de 1030 documentos, Reino Unido con 356, Australia con 140, Canadá con 103, Países Bajos con 88, España con 78, Alemania con 67, Suecia con 57, Israel con 56 y Brasil con 55 documentos al respecto. La Figura 5 ilustra los países con más aportaciones en el campo, en donde los colores más intensos reflejan mayores contribuciones, siendo evidente la poca aportación latinoamericana y, en particular, la colombiana, pese a las grandes implicaciones que el conflicto ha generado, como ya fue mencionado. En términos exactos dicho país se encuentra en la posición 15 de un total de 76 países incluidos en el reporte, con un total de 26 publicaciones. Junto a él, Chile, México, Argentina, Venezuela, Guatemala, Nicaragua y Perú, también son incluidos, aunque con contribuciones mínimas, siendo estas inferiores a las 12 publicaciones. 


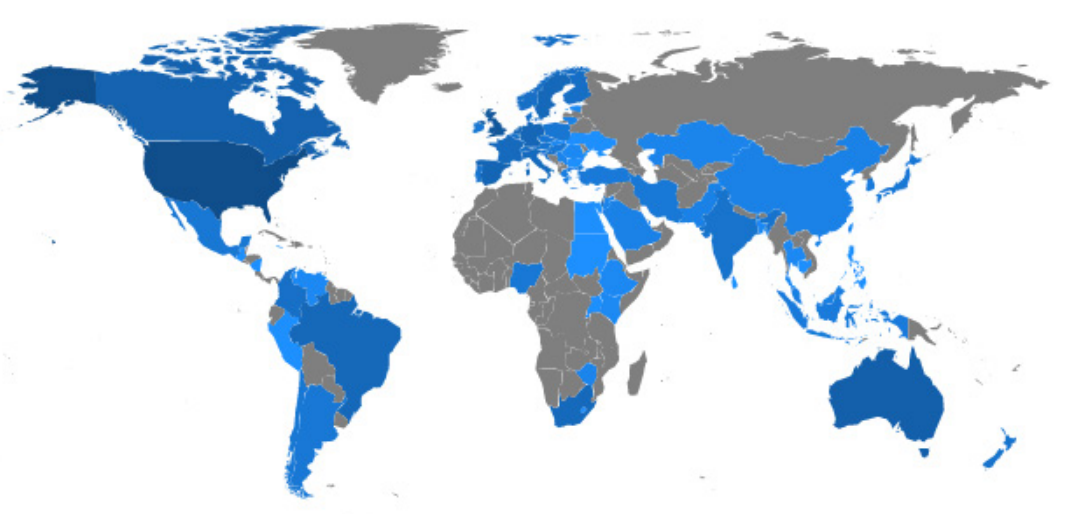

Figura 5. Países que más publican sobre el término "víctima". Fuente: Elaboración propia con Bibliometrix a partir de los datos analizados.

\section{Most Relevant Affiliations}

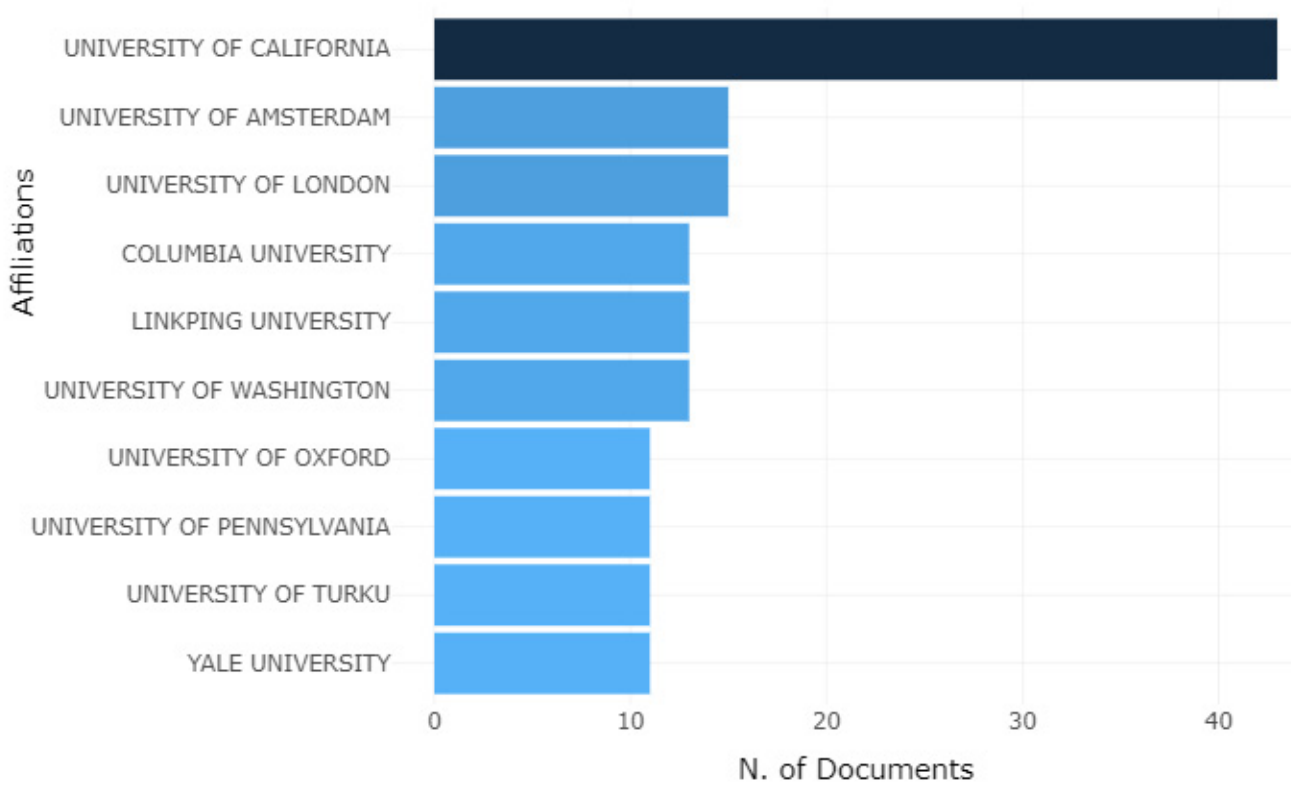

Figura 6. Instituciones que más aportan al conocimiento sobre "víctima". Fuente: Elaboración propia con Bibliometrix a partir de los datos analizados.

Adicionalmente, las instituciones que más aportan conocimiento sobre el concepto de "víctima" son: la Universidad de California con 43 documentos, la Universidad de Amsterbam y la Universidad de Londres, cada una con 15, las universidades de Columbia, Limpking 
y Washington con 13 cada una y las universidades de Oxford, Pennsylvania, Turku y Yale con 11 documentos cada una, tal como se ilustra en la Figura 6. Aunado a esto, en cuanto a las instituciones colombianas que han contribuido en este sentido, se pueden detallar la Universidad Nacional de Colombia, la Pontificia Universidad Javeriana, la Universidad de Los Andes, la Universidad Militar Nueva Granada, la Universidad Cooperativa de Colombia, la Universidad del Rosario, entre otras instituciones.

En cuanto a las palabras clave más utilizadas para los documentos que hacen alusión al concepto de "víctima", se encuentran: femenina, con una ocurrencia de 610 documentos; auto concepto, presente en 519 documentos; masculino, expuesto en 507 documentos; humano y humanos, presentes en 441 y 318 documentos, respectivamente; adulto, nombrada en 356 documentos; adolescente, en 310 documentos; artículo, en 278 documentos; víctimas de crimen en 215 documentos; y aspecto psicológico, presente en 211 documentos (Figura 7).

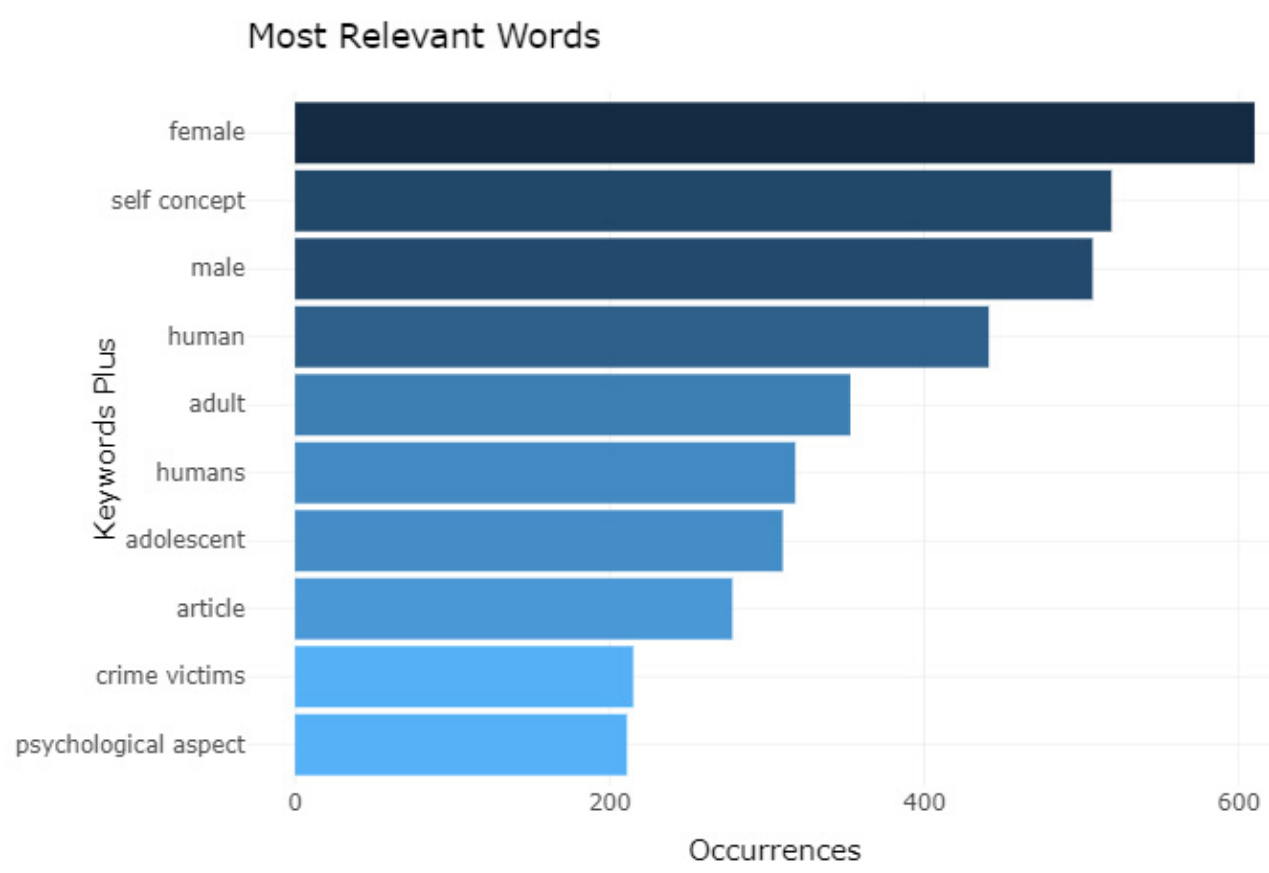

Figura 7. Palabras clave más frecuentes en artículos sobre "víctima" Fuente: Elaboración propia con Bibliometrix a partir de los datos analizados. 
En cuanto a la estructura conceptual del término, la Figura 8 señala tres grandes grupos, en lo que se refiere a la sincronía entre las palabras clave. Se tiene, por consiguiente, que quienes se refieren a víctima hacen alusión a aspectos psicológicos, humano(s), femenino, relaciones interpersonales, adultos jóvenes, cuestionario, Estados Unidos, juventud, auto concepto, adultos, agresión, masculino, relaciones humanas, estadística y víctima. Otro grupo se encuentra compuesto por quienes contribuyen al término desde la perspectiva de la niñez, los estudiantes, los adolescentes, el bullying, la psicología, la(s) víctima(s) de crimen(es) y la pareja; y, por último, hay quienes la refieren desde el comportamiento adaptativo, la adaptación y la psicología.

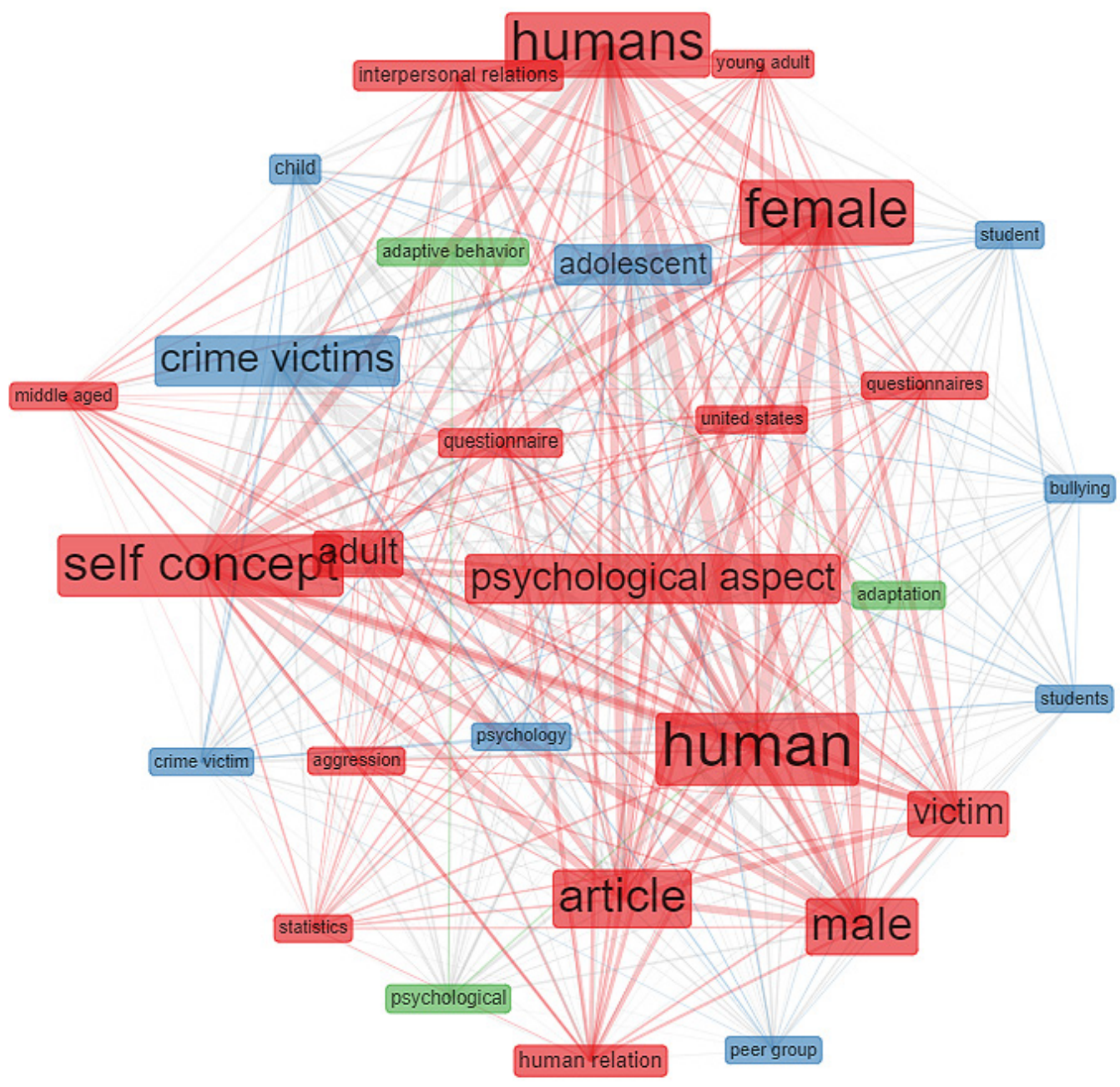

Figura 8. Relaciones entre palabras clave por grupo.

Fuente: Elaboración propia con Bibliometrix a partir de los datos analizados. 
Por último, haciendo alusión a los clústeres de investigación, cabe señalar que no se encontraron participaciones significativas y dinámicas entre los autores que más contribuyen en el campo, así tampoco entre las instituciones que más aportan a la concepción del término "víctima".

\section{Conclusiones}

Es incuestionable la poca claridad y aplicabilidad que se plantea del concepto en algunos escenarios teóricos, por ejemplo, los aportes planteados por Dussel (2001), uno de los precursores de la noción y quien afirma que las víctimas son auto responsables de su liberación y sujetos activos, no son del todo aplicables para el caso del conflicto colombiano, dadas las particularidades de este.

Si bien puede considerarse al ser humano como una persona racional, consciente de su acción, elección y preferencia, en el momento en que es considerada como víctima al haber sufrido un daño con ocasión del conflicto armado interno, debe superar además de esta circunstancia la limitación de oportunidades, fruto de la escasa prosperidad a nivel social y económico del país, lo que le impide acceder a una plataforma de oportunidades y autonomía, requeridas para la llamada liberación.

En cuanto a la definición de "víctima del conflicto armado colombiano" puede mencionarse un reconocimiento jurídico otorgado por la Ley 1448 (2011), aunque se evidencia ausencia en cuanto al reconocimiento social. La política de paz con legalidad, "desconoce pactos relacionados al enfoque territorial y la incorporación social efectiva de víctimas y victimarios" (Ravina-Ripoll, Gálvez-Albarracín y OtálvaroMarín, 2020). Es así como la concepción de víctima como sujeto histórico anteriormente mencionada, es olvidada en el momento que se afirma que solo es víctima la persona que hubiese sufrido un daño posterior al primero de enero del año 1985, pretendiendo así reparar a las víctimas de una fecha determinada, sin contemplar a las personas que sufrieron daños en años anteriores. La consciencia del pasado es un elemento que debe destacar.

El escenario teórico trazado por los diálogos de Shklar, Dussel, y Mate amplían el concepto, en tanto que víctima puede ser considerada como un ser humano, a quien su dignidad humana ha sido afectada 
por la violencia y violación de sus derechos, y también puede tener un papel activo en su reparación en tanto sean reconocidas e incluidas en las decisiones. Así mismo, la construcción del concepto de víctima a partir del conflicto armado colombiano ha sido un instrumento para la construcción de políticas públicas que establecen a la víctima como sujeto de reparación.

En tanto las definiciones que giran en torno al concepto, no involucran la participación directa o indirecta de las víctimas. El afectado es quien sufre las consecuencias y se debe tomar su palabra, para su real reconocimiento. Una participación efectiva, que tome su vivencia para la formulación, e implementación de proyectos, políticas y acciones es un camino por tejerse en la figura activa de víctima, dado que es un elemento imprescindible para hablar de la forma de reparación del daño material, físico, espiritual y emocional causado a las víctimas.

$\mathrm{Al}$ tenor de lo anterior, se puede afirmar que el concepto de víctima es actualmente arena de debate y discusiones, abarcando gran número de conceptos y formas de medición que están en constante transformación y evolución. Desde diferentes escuelas y áreas se han interesado en generar análisis y aportes que ayuden a interpretar este tópico y la totalidad de la complejidad existente.

El interés por el desagravio de las víctimas ha aumentado de forma considerable, debido al contexto global en que el conflicto armado ha emergido y la firma del Acuerdo Final para la Terminación del Conflicto y la Construcción de una Paz Estable y Duradera con las FARC-EP en el año 2016. En tanto la propuesta teórica de víctima, proporcionada por la Sentencia C-781 (2012) de la Ley 1448 (2011) desconoce elementos que deben ser incluidos: la heterogeneidad de las víctimas y las cuestiones relacionadas con la asistencia y reparación del daño de forma indisociable.

Junto a esto, el análisis bibliométrico que permite medir la contribución científica, cuantificando la calidad y repercusión de la misma, demuestra que, si bien Colombia es uno de los países que mayor número de víctimas ha generado, no tiene una aportación significativa en cuanto a producción, análisis aplicable también para el caso latinoamericano, por lo que hay un gran desafío en cuanto a consolidar la investigación de alto impacto en la región. 


\section{REFERENCIAS}

Beristain, A. (2000). Victimología: nueve palabras claves. México, D.F.: Tirant lo Blanch.

Bohórquez, L., Rojas, Y. y Anctil, P. (2017). De víctimas a sobrevivientes: el reto de la reconstrucción de memoria histórica en Colombia. Cambios y Permanencias, 8(2), 717-735. Disponible en https://revistas.uis.edu.co/index.php/revistacyp/ article/view/7810

Cobo, M., López-Herrera, A., Herrera-Viedma, E. y Herrera, F. (2011). Science mapping software tools: Reviw, analysis, and cooperative study among tools. JASIST, 62(7), 1382-1402. http:// dx.doi.org/10.1002/asi.21525

CNDH. (2018). Declaración sobre los principios fundamentales de justicia para las víctimas de delitos y del abuso de poder. México, D.F.: CNDH. Recuperado de https://www.cndh.org. $\mathrm{mx} /$ sites/default/files/documentos/2019-05/Justicia-VictimasDelito\%5B1\%5D.pdf

Dussel, E. (2001). Hacia una filosofía política crítica. Bilbao: Desclee de Brouwer.

García, R. (2019). Teoría de la justicia transicional y su vigencia en la reparación de niños, niñas y adolescentes víctimas del conflicto armado en Colombia. Jurídicas CUC, 15(1), 383-414. http://dx.doi.org/10.17981/juridcuc.15.1.2019.15

Henting, H. (1971). El delito. Madrid: Espasa-Calpe.

Hernández, J., Cerpa, A. y Molina, O. (2020). Marco jurídico de la paz en Colombia. Una revisión sistemática y crítica. Justicia, 25(38), 232-242. http://dx.doi.org/10.17081/just.25.38.4485

Jalecza. (2008). El concepto de víctimas en el acompañamiento psicosocial desde la perspectiva de los derechos humanos. [Post]. Bogotá, D.C.: Corporación AVRE. Recuperado de http://www. corporacionavre.org/wp-content/uploads/2015/03/EL-CONCEPTO-DE-VI\%CC\%81CTIMAS-.pdf

Levi, P. (1989). La zona gris - Los hundidos y los salvados. Barcelona: Ediciones Península. 
López, C. (2010). La refundación de la Patria, de la teoría a la evidencia. Bogotá, D.C.: Corporación Nuevo Arco-Iris.

Mendelshon, B. (1963). The Origin of the Doctrine of Victimology. Excerpta Criminológica, 3, 239-244.

Mora-Gámez, F. (2016). Reconocimiento de víctimas de conflicto armado en Colombia: Sobre tecnologías de representación y configuraciones de Estado. Universitas Humanistica, 82 (82), 75-101. http://dx.doi.org/10.11144/Javeriana.uh82. rvca

Narváez, B., Matzumoto, N., Mira, L. y Zúñiga, A. (2019). Los derechos e inclusión de las víctimas del conflicto armado vs. las obligaciones Estado colombiano. Jurídicas CUC, 15(1), 321-352. http://dx.doi.org/10.17981/juridcuc.15.1.2019.13

Neuman, F. (1994). Victimología. El rol de la víctima de los delitos convencionales. [ 2 ed.]. Buenos Aires: Editorial Universidad.

ONU. PNUD. (2014). Datos Colombia. [Online]. Disponible en https://www.co.undp.org/content/colombia/es/home.html

Ravina-Ripoll, R., Gálvez-Albarracín, E. y Otálvaro-Marín, B. (2020). Post acuerdo de paz: Una etapa a legitimar bajo el calediscopio de las Mipymes colombianas. Jurídicas CUC, 16(1), 303-322. http://dx.doi.org/10.17981/juridcuc.16.1.2020.13

República de Colombia. Congreso de la República. (10 de junio de 2011). Por la cual se dictan medidas de atención, asistencia y reparación integral a las víctimas del conflicto armado interno y se dictan otras disposiciones. [Ley 1448]. DO: 48.096. Disponible en https://www.unidadvictimas.gov.co/ es/ley-1448-de-2011/136531

República de Colombia. Corte Constitucional. (10 de octubre de 2012). Referencia: expediente D-8997. [Sentencia C-781]. MP: María Victoria Calle Correa. Disponible en https:// www.corteconstitucional.gov.co/relatoria/2012/C-781-12. htm 
República de Colombia. SNARIV. (abril 7, 2021). Así ha avanzado la reparación a las víctimas. Unidad para la Atención y la Reparación Integral a las Víctimas. Disponible en https://www. unidadvictimas.gov.co/es/9adonartuvoz/asi-ha-avanzado-lareparacion-integral-de-las-victimas-del-conflicto/61149

Reyes, M. (2008). Justicia de las víctimas. Terrorismo, memoria, reconciliación. Barcelona: Ánthropos.

Reyes, M. (2006). Medianoche en la historia, comentarios a las tesis de Walter Benjamin. Madrid: Trotta.

Robinson, J. A. (2016). La miseria en Colombia. Revista Desarrollo y Sociedad, (76), 9-88. http://dx.doi.org/10.13043/dys.76.1

Rojas, H. (2014). La víctima como nuevo sujeto histórico en la ética de la liberación en la edad de la globalización y la exclusión de Enrique Dussel. (Tesis de maestría). Universidad del Valle, Cali, Colombia. Recuperado de https://enriquedussel. com/txt/Textos-Tesissobre/2014.HernanMauricio.pdf

R Studio. (versión 1.4). IDE. [Software estadístico]. Boston: Rstudio. Disponible en https://www.rstudio.com/products/rstudio/

Shklar, J. (2013). Los rostros de la injusticia. Barcelona: Herder.

Spinak, E. (2001). Indicadores cienciométricos. ACIMED, 9(4), 4249. Recuperado de http://eprints.rclis.org/5163/1/sci07100. pdf

Trejos, L., Badillo, R. e Irreño, Y. (2019). El caribe colombiano: entre la construcción de paz y la persistencia del conflicto. Jurídicas CUC, 15(1), 9-46. http://dx.doi.org/10.17981/juridcuc.15.1.2019.01

Villamizar, C. (2019). Situación de violencia contra los defensores de derechos humanos en Colombia después del acuerdo de paz. Jurídicas CUC, 15(1), 209-228. http://dx.doi.org/10.17981/ juridcuc.15.1.2019.08

Vygotsky, L. (1964). Pensamiento y lenguaje. Buenos Aires: Lautaro. armado en Colombia desde la perspectiva FARC-EP. 
Deisy Milena Sorzano Rodríguez. Doctora en Estudios del Desarrollo Global. Magíster en Ciencias Sociales aplicadas a los estudios regionales y economista de profesión. Docente y líder de investigación, Tiempo Completo en Cetys Universidad (Tijuana, México). Línea de investigación: Desarrollo socio-económico, economía social, conflictos. https://orcid.org/0000-0002-4862-1442

Esthela Galván Vela. Doctora en Ciencias Administrativas. Máster en Comunicación Académica. Máster en Dirección Empresarial con énfasis en Administración Estratégica. Ingeniero Comercial. Profesor e Investigador de Tiempo Completo y Enlace del Centro de Excelencia en Competitividad y Emprendimiento de Cetys Universidad (Tijuana, México). Línea de Investigación: Emprendimiento e Innovación. https://orcid.org/0000-0002-8778-3989

María Eugenia Bonilla Ovallos. Doctorado en Estado de Derecho y Gobernanza Global de la Universidad de Salamanca (España). Especialización en Administración de Empresas de la Universidad Santo Tomás (Colombia). Pregrado en Economía de la Universidad Santo Tomás. Directora del Instituto en Estudios Políticos de la UNAB (Colombia). Línea de investigación: ciencia política, migración, liderazgo político. https://orcid.org/0000-0002-9456-0062

Rafael Ravina Ripoll. Doctor en Historia. Profesor de organización de empresas de la Universidad de Cádiz (España). Línea de investigación: Happiness Management, Felicidad y Emprendimiento Social. https://orcid.org/0000-0001-7007-3123 